\title{
A large opening and high flow rate piezoelectric pump with straight arm wheeled check valve
}

\author{
Lipeng He \\ Changchun University of Technology

\section{Zhe Wang} \\ Changchun University of Technology

\section{Da Zhao} \\ Changchun University of Technology \\ Jianming Wen \\ Zhejiang Normal University \\ Xiaochao Tian \\ Chang Chun University
}

Xiaoqiang Wu ( $\nabla$ wuxiaoqiang1995@126.com )

Changchun University of Technology https://orcid.org/0000-0001-8642-969X

\section{Original Article}

Keywords: Piezoelectric pump, Straight arm wheeled check valve, Valve parameter, Flow rate

Posted Date: April 2nd, 2020

DOI: https://doi.org/10.21203/rs.3.rs-18540/v1

License: (c) (i) This work is licensed under a Creative Commons Attribution 4.0 International License.

Read Full License 
1 A large opening and high flow rate piezoelectric 2 pump with straight arm wheeled check valve

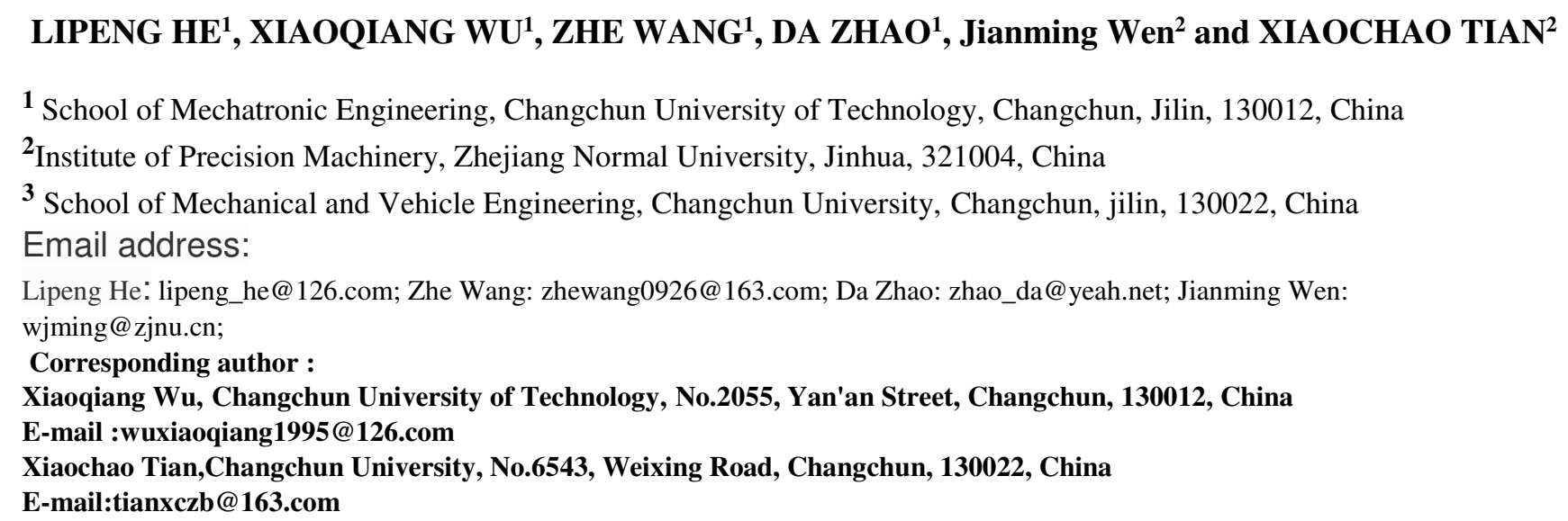

\section{Abstract}

Piezoelectric pumps are applied in cooling systems of microelectronic devices because of their small size. However, cooling efficiency is limited by low flow rate. A Straight arm wheeled check valve made of silica gel was proposed, which can improve flow rate of piezoelectric pump, solve the influence of glue aging on the sealing ability of a wheeled check valve and reduce the size of piezoelectric pump. This paper discusses the influence of valve arm number $(\mathrm{N}=2,3$ and 4), valve arm width $(\mathrm{W}=1.0,1.2$ and $1.4 \mathrm{~mm})$ and valve thickness $(\mathrm{T}=0.6,0.8$ and $1.0 \mathrm{~mm})$ on flow rate characteristics of piezoelectric pumps. When valve opening rises, the flow rate increases. The simulation results show that valves with 2 valve arms, $0.6 \mathrm{~mm}$ valve thickness and $1.0 \mathrm{~mm}$ valve arm width have maximum valve opening. Experimental results show that piezoelectric pumps with different valve parameters have different optimal frequencies. In addition, maximum flow rate is $431.6 \mathrm{~mL} / \mathrm{min}$ at $220 \mathrm{~V}$ and $70 \mathrm{~Hz}$. This paper provides a reference for the application of piezoelectric pump in cooling system.

Keywords: Piezoelectric pump, Straight arm wheeled check valve, Valve parameter, Flow rate

\section{Introduction}

Piezoelectric pumps[1] are widely used in the fields of bio-medicine [2-4], cooling systems for electronic components [56], fluid pumping systems [7-8], electronic sensors [9-11] and fuel delivery [12] due to simple structure, low power consumption and high stability.

According to whether there are valves or not, piezoelectric pumps can be divided into active valve piezoelectric pumps [13], passive valve piezoelectric pumps [14-16] and valveless piezoelectric pumps [17]. Passive valves, such as cantilever 
check valve should have low cracking pressure, low flow resistance and small reverse leakage. Currently, wheeled check valve is widely used in piezoelectric pump [22-26] as its low open pressure and good static performance. [27] However, wheeled check valves also have some disadvantages. The wheeled check valve is normally glued to fix [25] with the risk of fatigue ageing of the glue, which will cause to shorten the lifetime of the pump and affect the sealing capability of the switch. [27] The adhesive fixing method is also related to the fact that most of its materials are metal, such as beryllium bronze [24] and silicon [26]. In addition, metal materials also have the risk of permanent deformation and tearing. [28] In addition to adhesive fixation, adding a valve layer is another way to fix the valve, which can avoid a series of problems caused by adhesive aging. This structure requires an additional runner layer, but this will complicate the pump structure and require certain positioning of valve layer and runner layer. [29-30]

Studying the effect of valve structure on check valve piezoelectric pump can improve its performance, and researchers have done a great deal of effort. Research on curved arm wheeled check valve by some researchers focuses on the spring constant of the valve. The curved arm number is a parameter that has an obvious influence on the spring constant of wheeled check valve [31]. Valves with a small number of valve arms have a low spring constant and the flow rate of piezoelectric pumps is higher. When the number of curved arms is 2 , the thickness is $100 \mu \mathrm{m}$, the arm width is $50 \mu \mathrm{m}$, and the gap between folded beam sections is $50 \mu \mathrm{m}$, the spring constant is smallest, and the flow rate is about $5500 \mu l$. The valve with low spring constant has low opening pressure and small pressure loss, but the low spring constant will reduce the quick reset of the valve. [28] Valve designs with one or two folded beams could have a low spring constant but may suffer rotation movement and cause high leakage rates in the reverse direction. Only when the number of arms is greater than or equal to 3 , will the rotational movement not occur, which is called ortho-planar springs [32]. What's more, layer thickness, beam width and the gap between folded beam sections are also parameters that have influence on the spring constant. In order to further reduce the spring constants and leakage, two new valve designs with three folded beams are presented [29].These designs have lower spring constant, and at the same time secure the out-of-plane motion of the valve disc by increasing the length of the curved segments. The displacement and velocity of the piezoelectric actuator and the flow rate at all the operating frequency are affected by the thickness of the valve [30].

Structure of wheeled check valve also influences air block probability [33]. Curved arm wheeled check valves with different valve diameter ratios and thickness led to different air block probability. Low valve diameter ratios and thickness can decrease air block probability and improve stability of the piezoelectric pump. In order to have a better comparison 
between the piezoelectric pump in references, the performance of these pumps is listed in Table 1. One can observe that flow rate of most piezoelectric pumps is low. Piezoelectric pumps with large flow rate have large volume.

A large opening and high flow rate straight arm wheel valve made of silica gel was proposed. This article presents the design and fabrication of piezoelectric pumps and valves, and analyzes the influence of valve structure on the flow rate of piezoelectric pumps through experiments. This paper also studies the influence of valve arm number, valve arm width and valve thickness on flow rate through theoretical analysis. Valve opening at different valve parameters is simulated by ANSYS. Moreover, seven groups of straight arm wheeled check valve piezoelectric pumps with different valve parameters are designed and fabricated. The relationship between flow rate and valve parameters is analyzed according to the experiment result. This study provides a reference for high high flow rate piezoelectric pumps.

Table 1 Performance comparison of the presented piezoelectric pump in reference.

\begin{tabular}{ccccc}
\hline Reference & Year & Dimensions of micropump & Flow rate $(\mathrm{mL} / \mathrm{min})$ & $\begin{array}{c}\text { Flow rate per unit } \\
\text { volume }\left(\mathrm{mL} / \mathrm{mm}^{3}\right)\end{array}$ \\
\hline Ma et al [3] & 2016 & $40 \mathrm{~mm} \times 40 \mathrm{~mm} \times 10 \mathrm{~mm}$ & 9.1 & 0.0005 \\
Ma et al [6] & 2009 & $45 \mathrm{~mm} \times 28 \mathrm{~mm} \times 4 \mathrm{~mm}$ & 4.1 & 0.0008 \\
Fan et al & 2009 & $16 \mathrm{~mm} \times 16 \mathrm{~mm} \times 4 \mathrm{~mm}$ & 15.3 & 0.149 \\
$\quad[22]$ & & & & 0.00427 \\
Wang et al & 2019 & $50 \mathrm{~mm} \times 50 \mathrm{~mm} \times 20 \mathrm{~mm}$ & 213.5 & 0.0420 \\
$\quad[24]$ & & & & 0.0065 \\
Dong et al & 2017 & $50 \mathrm{~mm} \times 50 \mathrm{~mm} \times 16 \mathrm{~mm}$ & 1678.2 & 196 \\
$\quad$ [25] & 2015 & $50 \mathrm{~mm} \times 50 \mathrm{~mm} \times 12 \mathrm{~mm}$ & 196 & \\
Ma et al[26] & &
\end{tabular}

\section{Structure design}

\subsection{Pump design}

Fig.1 presents the structure of the piezoelectric pump. It mainly consists of pump cover, pump body, check valve, piezoelectric actuator (PZT), inlet and outlet. Piezoelectric actuators have been commercialized, with a size of $\emptyset 35 \mathrm{~mm} \times$ $0.34 \mathrm{~mm}$ being selected. Lead zirconate titanate (PZT) serves as the piezoelectric layer, and the diameter of piezoelectric layer is $\emptyset 25 \mathrm{~mm}$. The overall size of the pump is designed according to the size of the piezoelectric driver.The dimension of pump is $42 \mathrm{~mm} \times 42 \mathrm{~mm} \times 30 \mathrm{~mm}(\mathrm{~L} \times \mathrm{H} \times \mathrm{W})$. The O-rings are made of nitrile rubber and used to support the piezoelectric actuator and seal pump chamber. The space between the piezoelectric actuator and the pump body forms the pump chamber, with a diameter of $\emptyset 30 \mathrm{~mm}$. In order to improve the bubble dissolution and self-absorption capability of the pump, the dead volume of the pump chamber must be reduced. We adopt the method of reducing the chamber height to make the pump have low dead volume [34] and high compression rate. At the same time, it is considered that too low pump chamber height will produce flow resistance and the main purpose of the current study is to explore the effect of valve on performance, we simply referred to the forerunners' studies to choose chamber height of about $0.8 \mathrm{~mm}$. [35] In order to ensure that the opening of the 
valve is not affected by the height of the pump chamber, the valve seat is arranged in the groove on one side of the chamber bottom. A gap is left between the valve seat and the groove wall to provide a space for installing the valve. An inlet is arranged at that central position of the valve seat. The design of the valve seat is similar to that of a shoulder and is provided with a notch for providing space for the valve arm. The same is true for the valve seat design at the outlet. The design avoids the fixing mode of gluing, which will prolong the life of the pump and enhance the sealing ability of the switch.The pump body is adhesively connected with inlet and outlet with the inside diameter of $\varnothing 4.5 \mathrm{~mm}$ and the outside diameter of $\emptyset 6 \mathrm{~mm}$. The assembly is done by placing all pieces together layer-by-layer and then clamped together with fastening bolts.

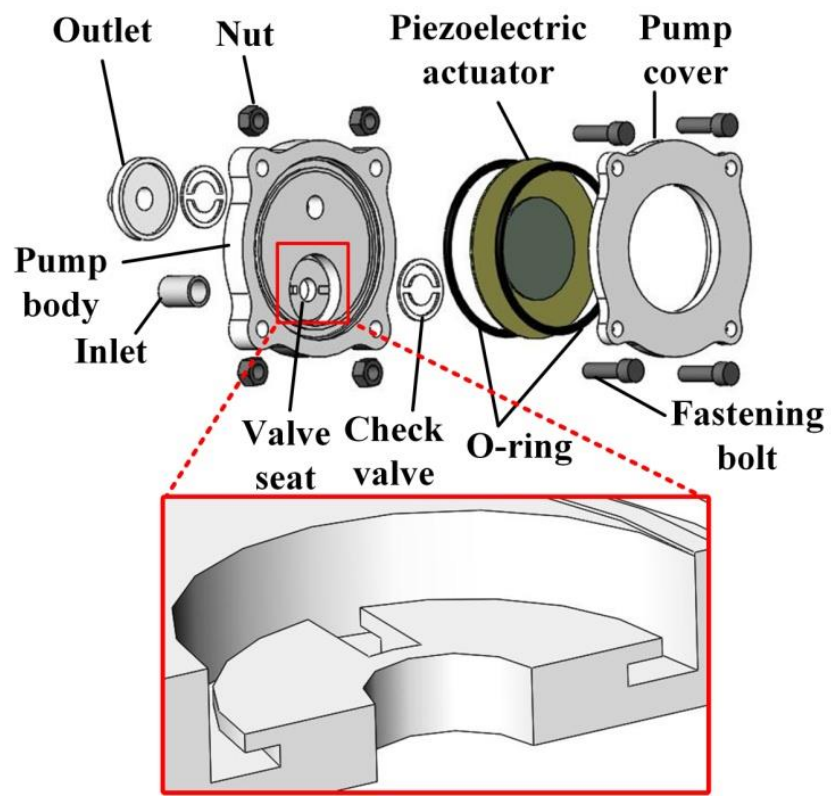

Fig.1. Structure of the piezoelectric pump

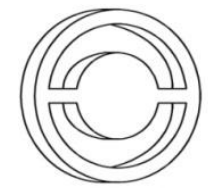

Valve 1 $\mathrm{N}=2, \mathrm{~W}=1, \mathrm{~T}=1$

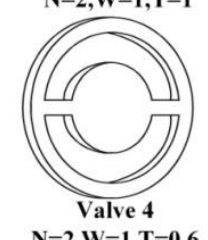

$\mathrm{N}=\mathbf{2}, \mathrm{W}=\mathbf{1 , T}=\mathbf{0 . 6}$

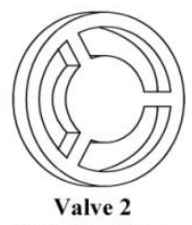

$\mathrm{N}=3, \mathrm{~W}=1, \mathrm{~T}=1$

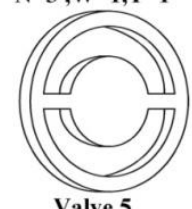

Valve 5

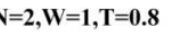

$\mathrm{N}=\mathbf{2}, \mathrm{W}=\mathbf{1}, \mathrm{T}=\mathbf{0}$

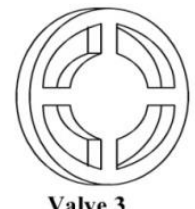

Valve 3
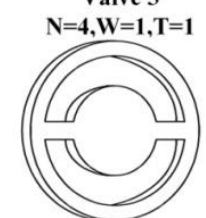

Valve 6

$\mathrm{N}=\mathbf{2}, \mathrm{W}=1.2, \mathrm{~T}=0.6$

Fixing ring

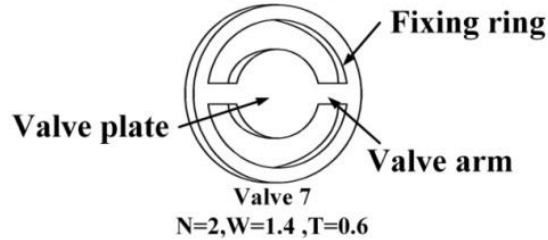

Fig.2. Different valve designs and their geometry parameters (in millimeter): N, valve arm number W, valve arm width T, valve thickness 
Fig.2 presents different valve designs and their geometry parameters. The wheeled check valve mainly consists of fixing ring,valve arm and valve plate. The sealing of the valve is ensured by the stress generated by the radial deformation of the valve arm. If the valve arm is designed to be curved, greater stress will be generated at the bend of the valve arm. Therefore, the valve arm is designed as a straight arm. Considering that the diameter of the pump chamber is $30 \mathrm{~mm}$, the outer diameter of the fixing ring is designed to be $12 \mathrm{~mm}$ and the inner diameter is designed to be $10 \mathrm{~mm}$. In order to reduce the air plug and ensure the sealing effect, we refer to previous studies and set the aperture to $4.5 \mathrm{~mm}$ and the valve plate diameter to $6 \mathrm{~mm}$.The diameter ratio of the valve is about 1.2. The 3D printer used in this paper has a higher precision guarantee above the size of $0.6 \mathrm{~mm}$. Therefore, the minimum value of valve parameter is $0.6 \mathrm{~mm}$. The other parameters of the seven silicone valves are the same except $\mathrm{N}, \mathrm{W}$ and $\mathrm{T}$.

\section{Theoretical analysis and simulation}

\subsection{Theoretical analysis}

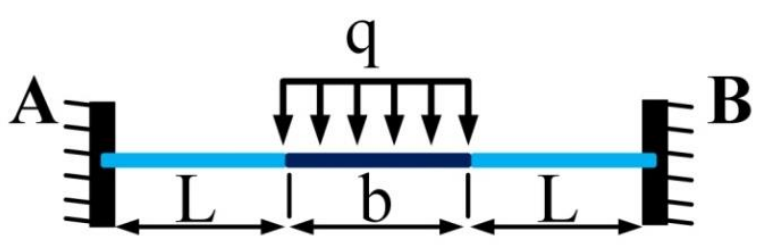

Fig. 3. Force diagram of check valve

Fig. 3 shows the force diagram of check valve. The valve is modeled as a fixed support beam at both ends.L is the length of the valve arm. $\mathrm{q}$ is the uniform load on the valve plate. $\mathrm{b}$ is the diameter of the valve plate. The valve opening can be obtained by the deflection of the beam. Deflection formula of beam fixed at both ends:

$$
K_{\max }=\frac{q b(2 L+b)}{384 E I}\left(2-2 \frac{b^{2}}{(2 L+b)^{2}}+\frac{b^{3}}{(2 L+b)^{3}}\right)
$$

Where $\mathrm{E}$ is the elastic modulus, $\mathrm{q}$ is the load on the valve plate, $\mathrm{I}$ is the moment of inertia of the cross section,

$$
\mathrm{I}=w t^{3} / 12
$$

Where $w$ is the width of the beam and $t$ is the thickness of the beam. The check valve is designed as a plate suspended on $N$ valve arms. When increasing the number of valve arms, it is equivalent to increasing the width of the beam, so, $w=N w_{1}$, $w_{1}$ is the width of a single valve arm. Thus, the valve opening can be obtained as follows

$$
K_{\max }=\frac{q b(2 L+b)}{32 E N w_{1} t^{3}}\left(2-2 \frac{b^{2}}{(2 L+b)^{2}}+\frac{b^{3}}{(2 L+b)^{3}}\right)
$$

According to Bernoulli equation, flow rate of the piezoelectric pump is obtained in zero pump head: 


$$
Q=C A \sqrt{\frac{2 \Delta P}{\rho}}=C \pi d K_{\max } \sqrt{\frac{2 \Delta P}{\rho}}
$$

Where $\mathrm{Q}$ is flow rate, $\mathrm{C}$ is velocity coefficient, $\mathrm{A}$ is the flow area, $\mathrm{r}$ is radius of valve plate, $\mathrm{k}$ is the opening degree of valve plate, $\rho$ is the liquid density, $\Delta \mathrm{p}$ is pressure difference between two sides of valve plate. From formula (1) to formula (4), it can be seen that flow rate is contacted with valve arm number $(\mathrm{N})$, valve arm width of $(\mathrm{W})$ and valve thickness $(\mathrm{T})$, the flow rate increases with the decrease of valve arm number, valve arm width and valve thickness.

124

\subsection{Simulation analysis}

Valves with different parameters have different valve opening under the same fluid load, thus causing piezoelectric pumps to have a different flow rate. ANSYS CFX and ANSYS Static Structural were used for valve opening. Firstly, we use ANSYS CFX to analyze the external flow field of the valve. Then ANSYS Static Structural is used to analyze the valve opening. The analysis result of the external flow field of the valve as a condition is used to carry out static analysis of the valve. In the numerical simulation, the fluid phase was water (density of $998 \mathrm{~kg} / \mathrm{m}^{3}$ ). The inlet speed was set to $0.446 \mathrm{~m} / \mathrm{s}$ at $300 \mathrm{~K}$, and outlet relative pressure was set to $1 \mathrm{~atm}$. The material of the straight arm wheeled check valve fabricated in this paper is silica gel (density of $870 \mathrm{~kg} / \mathrm{m}^{3}$, Young' Modulus of $120 \mathrm{MPa}$, Poisson's ratio of 0.48 ). The restriction of wheeled check valve mainly depends on valve arm, so it can be simplified in simulation. At last, simulation of valve opening at different valve arm number $(\mathrm{N})$, valve thickness $(\mathrm{T})$, valve arm width $(\mathrm{W})$ is obtained. The valve opening unit is millimeters.

As shown in Fig.4, simulated valve opening with different valve parameter is presented. Fig.(a),Fig.(b)and Fig.(c) show simulation of valve opening with different valve arm number. With the increase of valve arm, the valve opening decreases. Because under the same load, when valve arm number is larger, the force of each valve arm is smaller, and the deformation amount of each valve arm is smaller. When valve arm number is 2 , the area close to the valve arms is greatly constrained by the valve arms and the deformation of the valve is small, so the deformation of the valve center is not the largest. When valve arm number is 3 or 4 , the deformation in the middle of the valve is the largest because the restriction of the valve arm to the valve plate is uniform.

Fig.(a),Fig.(d) and Fig.(e) show the effect of valve thickness on valve opening when the optimal number of valve arms is 2. It can be seen that valves with different thicknesses have different valve deformation differences. Valves with large thicknesses have small deformation differences in different parts of the valve and have smaller valve opening. Because the larger the thickness, the larger the moment of inertia of the cross section. Large moment of inertia of the cross section makes valve opening small. 
After determining the influence of valve arm number and valve thickness on the valve opening, we set these two parameters as the best, and further studied the influence of the valve arm width on the valve opening. Fig. (d),Fig.(f) and 148 Fig.(g) present simulation of valve opening with different valve arm width. With the width of the valve arm increases, not only the deformation of the valve arm decreases, but also the deformation of the valve plate portion decreases. The increase of the valve arm width increases the restriction of the valve arm to the valve plate. Valve arm width can also change the moment of inertia of the cross section. The wider the valve arm width, the smaller the moment of inertia of the cross section.

(a)

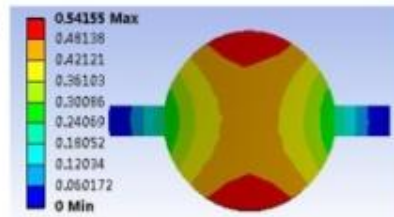

(d)

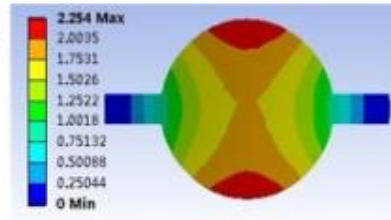

(g)

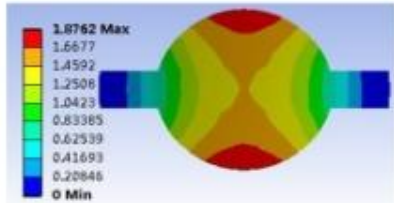

(b)

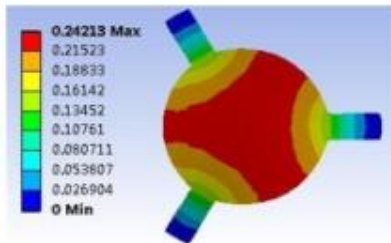

(e)



(c)

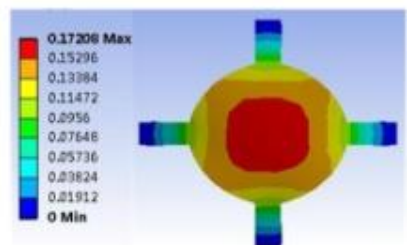

(f)

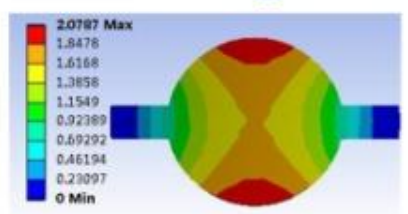

Fig. 4. Simulation of valve opening with different valve parameter (a) $\mathrm{N}=2, \mathrm{~W}=1, \mathrm{~T}=1$ (b) $\mathrm{N}=3, \mathrm{~W}=1, \mathrm{~T}=1$ (c) $\mathrm{N}=4, \mathrm{~W}=1, \mathrm{~T}=1$ (d) $\mathrm{N}=2$, $\mathrm{W}=1, \quad \mathrm{~T}=0.6 \quad$ (e) $\quad \mathrm{N}=2, \quad \mathrm{~W}=1, \quad \mathrm{~T}=0.8 \quad$ (f) $\quad \mathrm{N}=2, \quad \mathrm{~W}=1.2, \quad \mathrm{~T}=0.6 \quad(\mathrm{~g}) \quad \mathrm{N}=2, \quad \mathrm{~W}=1.4, \quad \mathrm{~T}=0.6$

\section{Fabrication and Experiment setups}

\subsection{Fabrication}

Beryllium bronze and silicon are commonly used as valve materials, but their elastic modulus is greater than that of silica gel. In order to reduce the spring constant of the valve, silica gel is selected. The valve can be obtained by fully mixing silica gel and curing agent at a ratio of 100:1, pouring into a mold, flattening the surface of the silica gel through a scraper, and standing for 5 hours. After the silica gel is completely solidified, it is taken out of the mold.

The FDM 3D printer (JGAURORA) uses PLA material to fabricate pump cover, pump body, inlet and outlet. 3D printing slicing was carried out with Cura software, and the 3D printing parameters are shown in the Table 2. The actual pump and valve are illustrated in fig. 5 . 
Table 2 3D printing parameter setting

\begin{tabular}{cc}
\hline Setting & Parameters \\
\hline Layer height $(\mathrm{mm})$ & 0.05 \\
Shell thickness $(\mathrm{mm})$ & 0.8 \\
Fill Density $(\%)$ & $60 \%$ \\
Print speed $(\mathrm{mm} / \mathrm{s})$ & 80 \\
Printing temperature $\left({ }^{\circ} \mathrm{C}\right)$ & 210 \\
Bed temperature $\left({ }^{\circ} \mathrm{C}\right)$ & 60 \\
Support Type & Everywhere \\
Platform adhesion type & Raft \\
Diameter $(\mathrm{mm})$ & 1.75 \\
Flow $(\%)$ & 100.0 \\
\hline
\end{tabular}

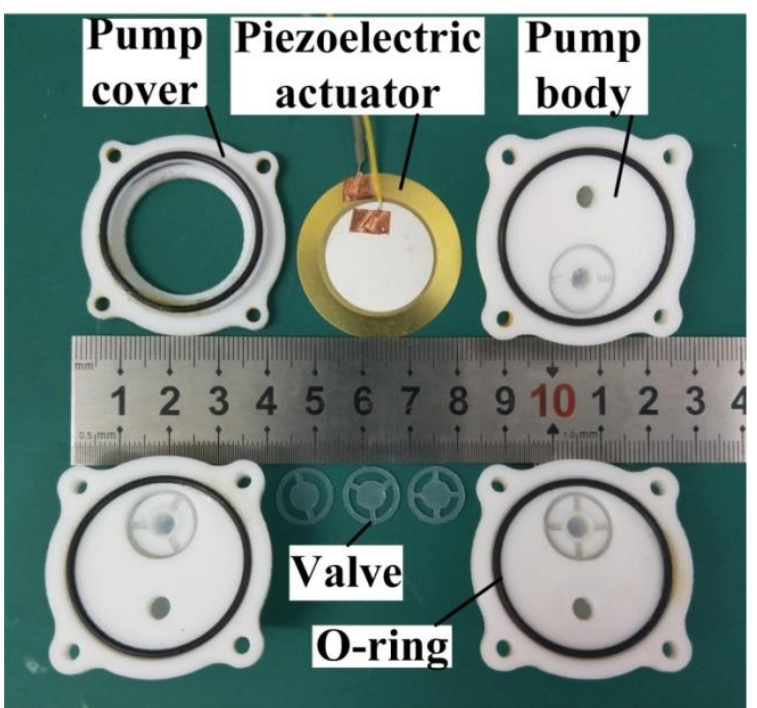

Fig. 5.Photo of the prototype pump and valve

\subsection{Experimental setups}

In order to study the influence of valve parameters on flow rate, a series of experiments were carried out. The entire experimental setup is illustrated in Fig. 6.Water was utilized as the working medium at $25^{\circ} \mathrm{C}$. The piezoelectric pump is fixed by clamps, and the inlet and outlet are respectively connected with rubber pipes. A sinusoidal voltage and frequency are generated by a signal generator (CUH, SDVC40-S, Nanjing, China, range of voltage: 0-220V, range of frequency: 40$400 \mathrm{~Hz}$ ). The flow rate is measured by an electronic balance with a division value of $0.1 \mathrm{~g}$ per minute. By sweeping frequency 
every $5 \mathrm{~Hz}$ from $40 \mathrm{~Hz}$ to $120 \mathrm{~Hz}$ at optimal voltage, the flow rate curve with frequency is obtained. The flow rate curve with voltage can also be obtained by sweeping voltage every $5 \mathrm{~V}$ from $150 \mathrm{~V}$ to $220 \mathrm{~V}$ at the optimal frequency. Flow test experiments of piezoelectric pumps can be carried out through these experimental devices.

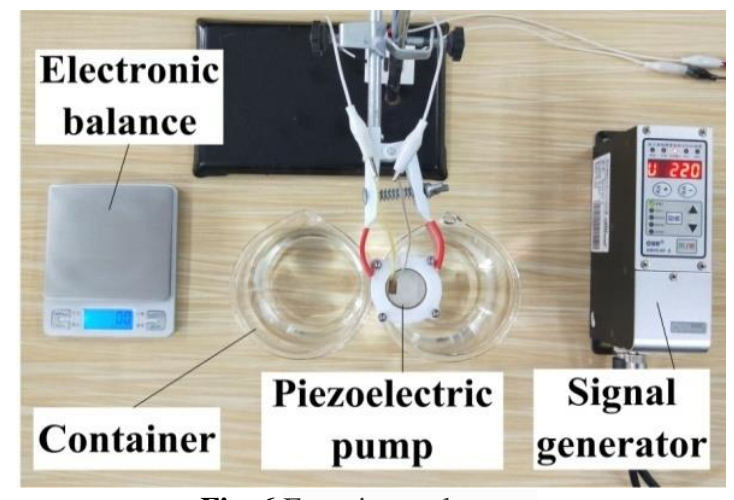

Fig. 6.Experimental setups

\section{Results and discussion}

\subsection{The relationship between valve arm number and flow rate}

As seen in Fig. 7, it is observed that the flow rate increases first and then declines gradually with increasing frequency. As the frequency increases, the number of times the piezoelectric pump works per unit time increases, thus flow rate increases. When the optimal frequency point is reached, the flow rate of the piezoelectric pump reaches the maximum. At $220 \mathrm{~V}$, when valve arm number is 2,3 and 4 respectively, the maximum flow rate is $370 \mathrm{~mL} / \mathrm{min}$ at $65 \mathrm{~Hz}, 303.8 \mathrm{~mL} / \mathrm{min}$ at $70 \mathrm{~Hz}$ and $226.4 \mathrm{~mL} / \mathrm{min}$ at $65 \mathrm{~Hz}$. When the frequency increases further, flow rate drops because of the valve hysteresis. When the phase lag of the check valve with respect to the piezoelectric actuator exceeded one cycle; the check valve was matched with the next cycle of the piezoelectric actuator, and the output flow rate started to increase again.[36] So there is a peak in the second half of the curve. What's more, the optimal frequency varied for the increasing number of arms. The frequency of the pump system is related to the natural frequency of the valve. When the natural frequency of the valve is large, the frequency of the pump system is also large. As the number of valve arms increases, the optimal frequency rises first and then falls. The natural frequency of the wheeled check valve is determined by the ratio of the stiffness and mass of the valve. When the number of valve arms increases from 2 to 3 , the stiffness of the wheeled check valve increases significantly, so the natural frequency increases. When the number of valve arms is 4 , compared with the number of valve arms is 2 , the stiffness and mass of the wheeled check valve increase, so the natural frequency remains unchanged. In Fig. 8, there is a steady growth with the increase of voltage. The amplitude of the piezoelectric actuator will rise as the voltage increases, thus making the chamber volume large. Negative pressure caused by the increase of the chamber volume increases, causing the increase in flow rate. 


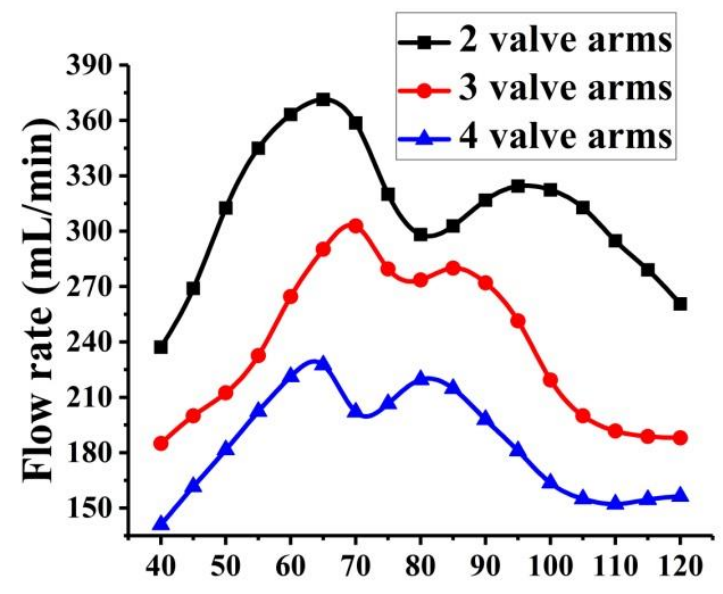

Frequency $(\mathrm{Hz})$

Fig. 7. The flow rate curve with frequency under different valve arm number



Fig. 8. The flow rate curve with voltage under different valve arm number

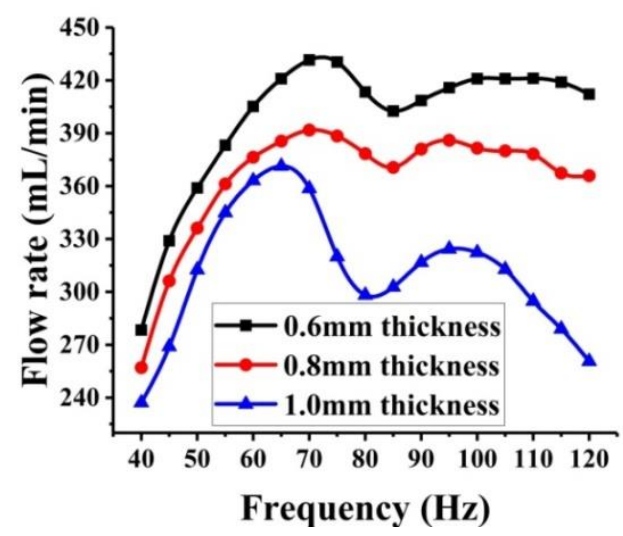

Fig. 9.The flow rate curve with frequency under different valve thickness 




Fig. 10.The flow rate curve with voltage under different valve thickness

After analyzing the influence of the valve arm number on the flow rate, the valve arm number of 2 was selected. The valve arm width is set to $1 \mathrm{~mm}$. Fig. 9 and Fig. 10 show the experiment result of flow rate with the valve thickness of 0.6/0.8/1.0mm. From Fig. 9, the flow rate goes up first and then goes down with the increasing frequency. As the frequency increases, there will be a phase difference between the valve and the piezoelectric actuator, and a local peak will appear at the place where the phase difference between the two is the smallest. In the high frequency range, it is obvious that the curve with a valve thickness of $1 \mathrm{~mm}$ drops faster. The increase in thickness makes the stiffness larger, which will reduce the vibration of the valve. The phase difference between the valve and the piezoelectric actuator becomes large. Therefore, the valve curve with a valve thickness of $1 \mathrm{~mm}$ drops faster. The thicker valve will also make it difficult to open the valve, thus reducing the flow rate. The flow rate is relatively large when the valve thickness is $0.6 \mathrm{~mm}$. In addition, the optimal frequency decreased with increasing membrane thickness. As the thickness increases, the mass of the wheeled check valve increases, so its natural frequency increases. Therefore, when the thickness of the wheeled check valve is $0.6 \mathrm{~mm}$, the optimal frequency point of the piezoelectric pump is the largest. When the valve thickness is $0.6 \mathrm{~mm}$ and $0.8 \mathrm{~mm}$, the flow fluctuation is less after second optimal frequency, which indicates that the thin valve has a wide operating frequency. At the optimal frequency, the relationship between voltage and different valve thickness $(0.6,0.8$ and $1 \mathrm{~mm})$ is shown in Fig. 10. There has been a gradual rise as increasing voltage. The greater the voltage is, the greater the load on the valve and the greater the valve opening. The thicker the valve, the harder it is to open it, the flow rate decreases. The maximum flow rate of piezoelectric pump with $0.6 \mathrm{~mm}$ thickness is $431.6 \mathrm{~mL} / \mathrm{min}$ at $220 \mathrm{~V}$ and $70 \mathrm{~Hz}$. Compared with $0.6 \mathrm{~mm}$ valve thickness, the valve opening of other valve thickness $(0.8$ and $1.0 \mathrm{~mm})$ is low, thus causing the flow rate drops.

\subsection{The relationship between valve arm width and flow rate}



valve thickness is set to 2 and $0.6 \mathrm{~mm}$, respectively. In Fig. 11, the relationship between flow rate and frequency is presented. The curves trend is similar to flow rate curves of different valve thickness. As the frequency increases, the flow rate first rises and then declines. At $220 \mathrm{~V}$, it can be seen intuitively from the diagram that the flow rate of piezoelectric pump with $1.0 \mathrm{~mm}$ is the optimal when the frequency is $70 \mathrm{~Hz}$. The optimal frequency stayed the same for increasing arm width. Fig. 12 reveals that there has been a steady rise with the increase in voltage. The flow rate of piezoelectric pump with $1.0 \mathrm{~mm}$ valve arm width is optimal at $220 \mathrm{~V}$ and $70 \mathrm{~Hz}$. When the valve arm width rises, valve opening will decline, thus causing the flow rate to fall.

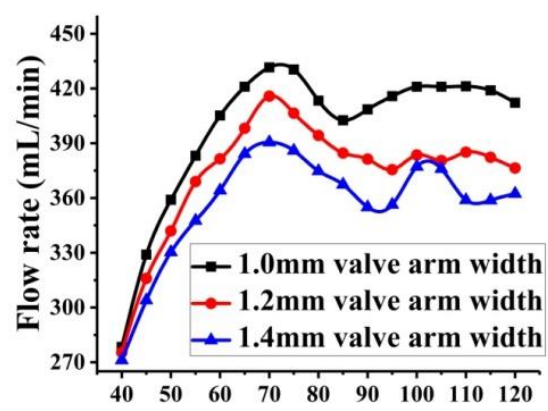

Frequency $(\mathrm{Hz})$

Fig. 11. The flow rate curve with frequency under different valve arm width

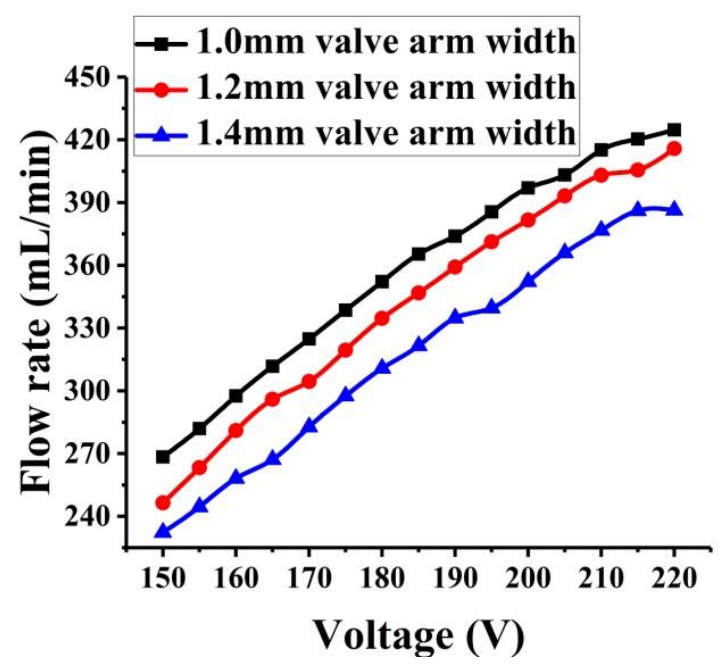

Fig. 12.The flow rate curve with voltage under different valve arm width 


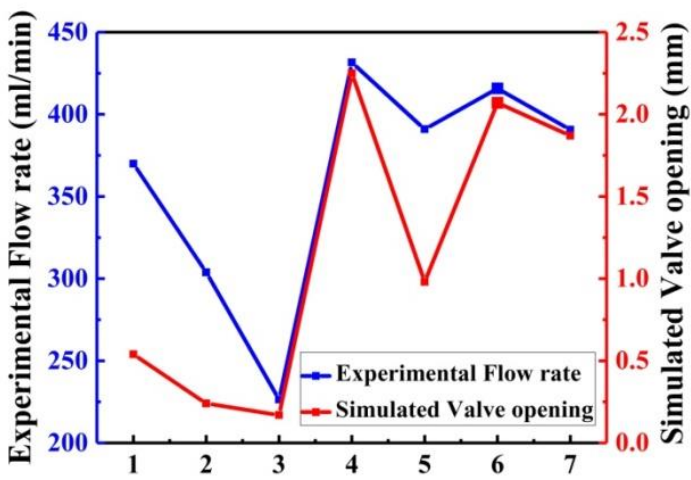

Valve

Fig. 13.Relationship between valve opening (simulation) and flow rate (experiment)

The relationship between the highest flow rate in the experiment and highest simulated valve opening of each valve is shown in Fig. 13. It is found that the highest flow rate in the experiment and highest simulated valve opening have same the variation tendency. The flow rate of the piezoelectric pump corresponding to the valve with a large opening is also large. As the number of valve arms increases, the valve opening becomes smaller and the flow rate of piezoelectric pump decreases, such as valve 1 , valve 2 and valve 3 . As the thickness increases, the valve opening decreases and the pump flow drops, such as valve 4 , valve 5 and valve 1 . With the increase of valve arm width, the valve opening becomes smaller and the flow rate of piezoelectric pump decreases, such as valve 4, valve 6 and valve 7 . In addition, the number of valve arms and the thickness of the valve have greater influence on the flow rate of the piezoelectric pump than the width of the valve arm.

\section{Conclusion}

In this paper, the influence factors of high flow rate are discussed. Seven groups of straight arm wheeled check valve piezoelectric pumps with different parameters were designed. The working principle was analyzed. The theoretical analysis of the flow rate of the straight arm wheeled check valve piezoelectric pump was also presented. ANSYS CFX and ANSYS Static Structural were used to simulate valve opening. The prototype was fabricated by 3D printer. The flow rate of the straight arm wheeled check valve piezoelectric pump was measured. The experimental results show that the valve arm number, the valve thickness and the valve arm width affect not only the optimum frequency but also the frequency bandwidth of the straight arm wheeled check valve piezoelectric pump. Piezoelectric pump with 2 valve arm number, $0.6 \mathrm{~mm}$ thickness and 1.0 valve arm width has the best flow rate of $431.6 \mathrm{~mL} / \mathrm{min}$ at $220 \mathrm{~V}$ and $70 \mathrm{~Hz}$. What's more, decreasing valve arm number, valve thickness and valve arm width can increase flow rate at high frequency range. Due to its high flow rate, the piezoelectric pump is expected to be widely used in cooling systems. 
The datasets used and/or analysed during the current study are available from the corresponding author on reasonable request.

\section{Competing interests}

269 The authors declare that they have no competing interests.

\section{$270 \quad$ Founding}

271 This paper was funded by financial support from Youth Science Foundation under Grant 51705031 and Science and 272 Technology Department Project under Grant 20190103050JH in the design of the study and collection, analysis, and 273 interpretation of data and in writing the manuscript.

\section{Authors' contributions}

275 L.H. and X.W. conceived and designed the experiments. X.C. performed the experiments. X.C, D.Z., and Z.W. analyzed the data. J.W. contributed materials and analysis tools. X.W. wrote the paper. All authors read and approved the final manuscript.

278

\section{Acknowledgements}

The authors would like to acknowledge the financial support from Youth Science Foundation under Grant 51705031and Science and Technology Department Project under Grant 20190103050JH.

\section{References}

[1] Santiago, D. J. L. J. G. . (2004). Topical review: a review of micropumps. Journal of Micromechanics \& Microengineering, 14(6), R35R64.

[2] Cui, Q. , Liu, C. , and Zha, X. F. . (2007). Study on a piezoelectric micropump for the controlled drug delivery system. Microfluidics and Nanofluidics,3(4), 377-390.

[3] Ma, H. K. , Chen, R. H. , Yu, N. S. , and Hsu, Y. H. . (2016). A miniature circular pump with a piezoelectric bimorph and a disposable chamber for biomedical applications. Sensors and Actuators A: Physical,251, 108-118.

[4] Song Chen, Xinyi Xie, Junwu Kan, Jiajian Ji, Zhonghua Zhang, Jianping Li. (2019). A hydraulic-driven piezoelectric pump with separable channel for drug delivery [J]. Sensors and Actuators A: Physical, 2019,295.

[5] Singhal, V., and Garimella, S. (2005). A novel valveless micropump with electrohydrodynamic enhancement for high heat flux cooling. IEEE Transactions on Advanced Packaging,28(2), 230.

[6] Ma, H. K. , Chen, B. R. , Gao, J. J. , and Lin, C. Y. . (2009). Development of an oapcp-micropump liquid cooling system in a laptop. International Communications in Heat and Mass Transfer,36(3), 225-232.

[7] Roberts, D. C. , Li, H. , Steyn, J. L., Yaglioglu, O. , Spearing, S. M. , and Schmidt, M. A. , et al. (2003). A piezoelectric microvalve for compact high-frequency, high-differential pressure hydraulic micropumping systems.Journal of Microelectromechanical Systems, 12(1), 81-92. 
[8] Zhang, Z. , Kan, J. , Cheng, G. , Wang, H. , and Jiang, Y. . (2013). A piezoelectric micropump with an integrated sensor based on space-division multiplexing.Sensors and Actuators A: Physical,203, 29-36.

[9] Lee, S. C. , Hur, S. , Kang, D. , Kim, B. H. , and Lee, S. J. . (2016). The performance of bioinspired valveless piezoelectric micropump with respect to viscosity change.Bioinspiration and Biomimetics, 11(3), 036006.

[10] Zhang, Z. , Kan, J. W. , Wang, S. , Wang, H. , Ma, J. , and Jiang, Y. . (2015). Development of a self-sensing piezoelectric pump with a bimorph transducer.Journal of Intelligent Material Systems and Structures, 1045389X15575082.

[11] Ham, Y. B., Song, J. J. , Park, J. H. , Yun, S. N. , and Ahn, K. Y. . (2006). A study on the small size PZT pump for cooling water circulation.SICE-ICASE, 2006. International Joint Conference. IEEE.

[12] Kjeang, E. , Djilali, N. , and Sinton, D. (2009). Microfluidic fuel cells: a review.Journal of Power Sources, 186(2), 353-369.

[13] Sun Yeming ; Wang Junyao ,(2019), Digitally-controlled driving power supply for dual-active-valve piezoelectric pump. MICROSYSTEM TECHNOLOGIES-MICRO-AND NANOSYSTEMS-INFORMATION STORAGE AND PROCESSING SYSTEMS ,25(4),1257-1265

[14] Junwu, K. , Zhigang, Y. , Taijiang, P. , Guangming, C. , and Boda, W. .(2005). Design and test of a high-performance piezoelectric micropump for drug delivery. Sensors and Actuators A (Physical),121(1), 156-161.

[15] P. Zeng, L. Li, J. Dong, G. Cheng, J. Kan, F. Xu.(2016) Structure design and experimental study on single-bimorph doubleacting check-valve piezoelectric pump,Proceedings of the Institution of Mechanical Engineers, Part C, Arch. J. Mech. Eng. 230 (14), 2339-2344,

[16] M. Adams, N. Turner, P. Pollard.(2008) A study of annulus lubrication for oil well completion using scale model tests, OCEANS $20081-8$

[17] Fathima, M. , Gehan, M. , Chamitha, A. , Hiniduma, C. , Ranjith, A. , and Pubudu, K. , et al. (2018). Development of pzt actuated valveless micropump.Sensors, 18(5), 1302-.

[18] Esashi, M., Shoji, S. , and Nakano, A. .(1989). Normally closed microvalve and mircopump fabricated on a silicon wafer.Sensors and Actuators, 20(1-2), 163-169.

[19] Shoji, S. , and Esashi, M. .(1989). Fabrication of a micropump for integrated chemical analyzing systems.,72(10), 52-59.

[20] Wang, X. Q. , Lin, Q. , and Tai, Y. C. . (1999). A Parylene micro check valve. Micro Electro Mechanical Systems, 1999. MEMS '99. Twelfth IEEE International Conference on. IEEE.

[21] Nguyen, N. T. , and Truong, T. Q. .(2004). A fully polymeric micropump with piezoelectric actuator.Sensors and Actuators B (Chemical),97(1), 137-143.

[22] Fan, Zunqiang, et al. (2009)Study on the large flow rate piezoelectric mini-pump with metal check valve. .MECHATRONICS and Automation

[23] Dong, Jing Shi , et al. (2017). Design and experimental research on piezoelectric pump with triple vibrators.Microsystem Technologies,23(8), 3019-3026. 

support.Micromachines.

[25] Dong, J. S. , Liu, R. G., Liu, W. S. , Chen, Q. Q. , Yang, Y., and Wu, Y., et al. (2017). Design of a piezoelectric pump with dual vibrators.Sensors and Actuators A: Physical,257, 165-172.

[26] Ma, H. K. , Chen, R. H. , and Hsu, Y. H. .(2015). Development of a piezoelectric-driven miniature pump for biomedical applications. Sensors and Actuators A: Physical,234, 23-33.

[27] Peng, Taijiang,Guo, Qiuquan,Yang, Jun,Xiao, Junfeng,Wang, Hao,Lou, Yan,Liang, Xiong.(2019) Sensors andActuators B-

[28] Li, B., Chen, Q. , Lee, D. G., Woolman, J. , and Carman, G. P. . 2005. Development of large flow rate, robust, passive micro check valves for compact piezoelectrically actuated pumps.Sensors and Actuators A Physical,117(2), 325-330.

[29] Truong, T. Q. , and Nguyen, N. T. .(2004). A polymeric piezoelectric micropump based on lamination technology.Journal of Micromechanics and Microengineering, 14(4), 632-638.

341 [30] Cheng, C. H. , and Tseng, Y. P. .(2013). Characteristic studies of the piezoelectrically actuated micropump with check valve.Microsystem Technologies,19(11), 1707-1715.

343 [31] Nguyen, N. T., Truong, T. Q., Wong, K. K., Ho, S. S., and Low, L. N. .(2004). Micro check valves for integration into polymeric microfluidic devices.Journal of Micromechanics and Microengineering,14(1), 69-75.

345 [32] Parise, J. J. , Howell, L. L. , and Magleby, S. P. (2001). Ortho-planar linear-motion springs.Mechanism and Machine Theory,36(11-12), 1281-1299.

347 [33] Song Chen, Yong Liu, Yanhu Shen, Jiantao Wang and Zhigang Yang (2015).The Structure of Wheel Check Valve Influence on Air Block Phenomenon of Piezoelectric Micro-Pump MICROMACHINES-BASEL2015, 6, 1745-1754

[34] Farshchi Yazdi, S. A. F. , Corigliano, A. , and Ardito, R. . (2019). 3-d design and simulation of a piezoelectric micropump.Micromachines, 10(4).

351 [35] Ping, Z. , Ming, C. G. , Long, L. J. , Feng, S. X. , and Long, Z. Y. . (2005). Experimental research on double-chambered piezoelectric pump with membrane valves.Optics and Precision Engineering.

[36] Yong Tang, Mingze Jia, Xinrui Ding, Zongtao Li, Zhenping Wan, Qinghong Lin, Ting Fu.(2019). Experimental investigation on thermal management performance of an integrated heat sink with a piezoelectric micropump. Applied Thermal Engineering. 
Figures

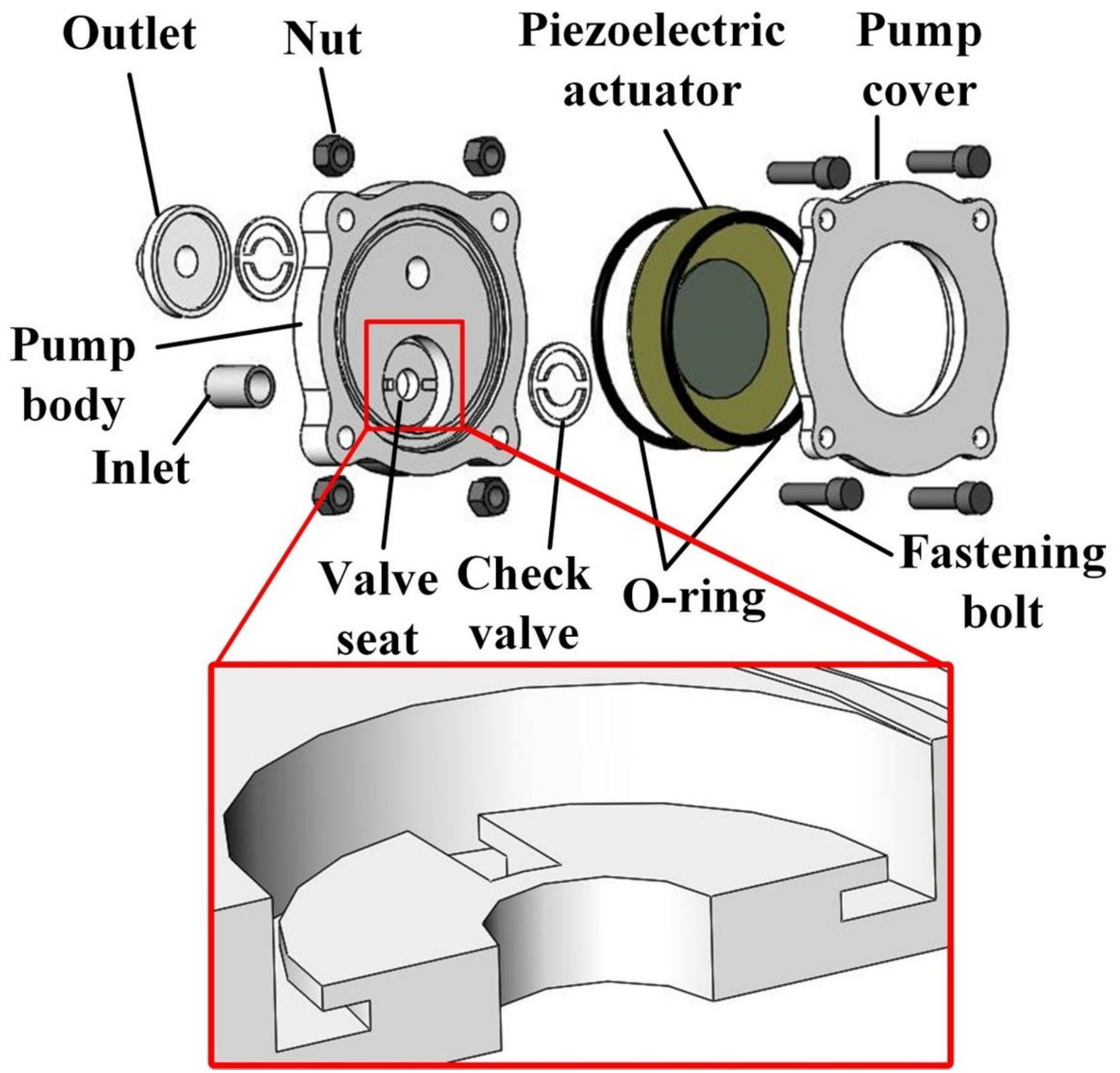

Figure 1

Structure of the piezoelectric pump 

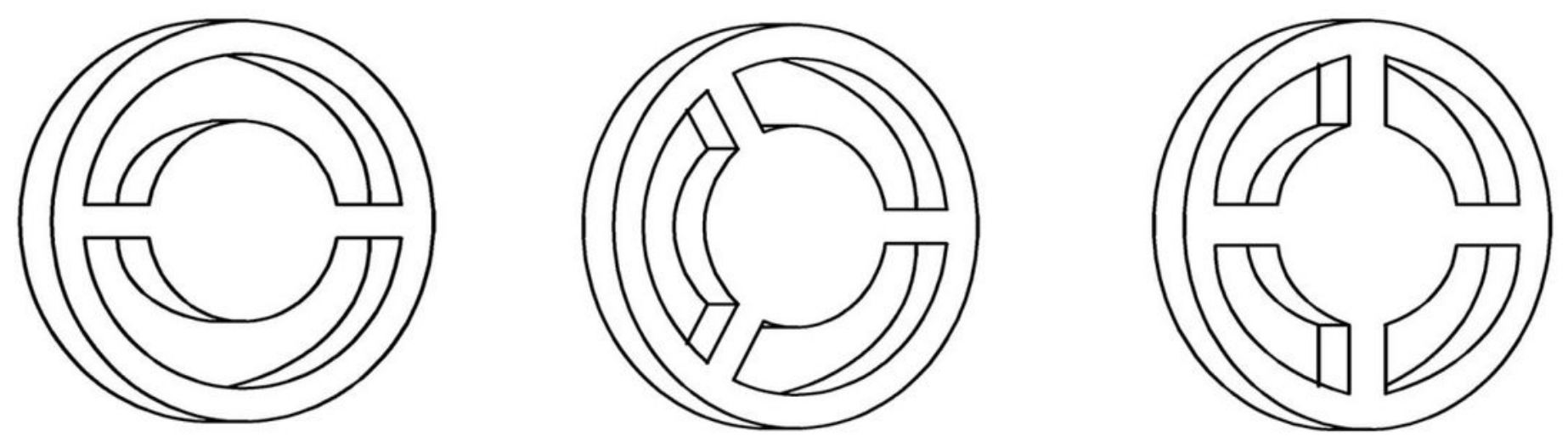

Valve 1

Valve 2

Valve 3

$\mathrm{N}=\mathbf{2}, \mathrm{W}=1, \mathrm{~T}=1$


Valve 5

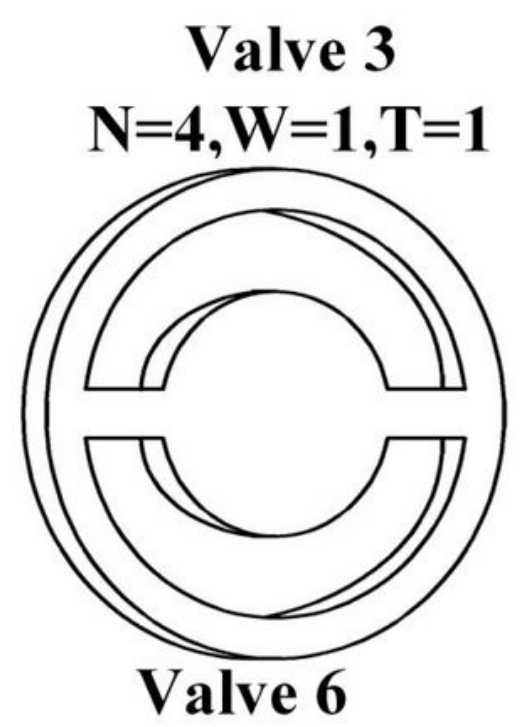

$\mathrm{N}=2, \mathrm{~W}=1, \mathrm{~T}=0.6$
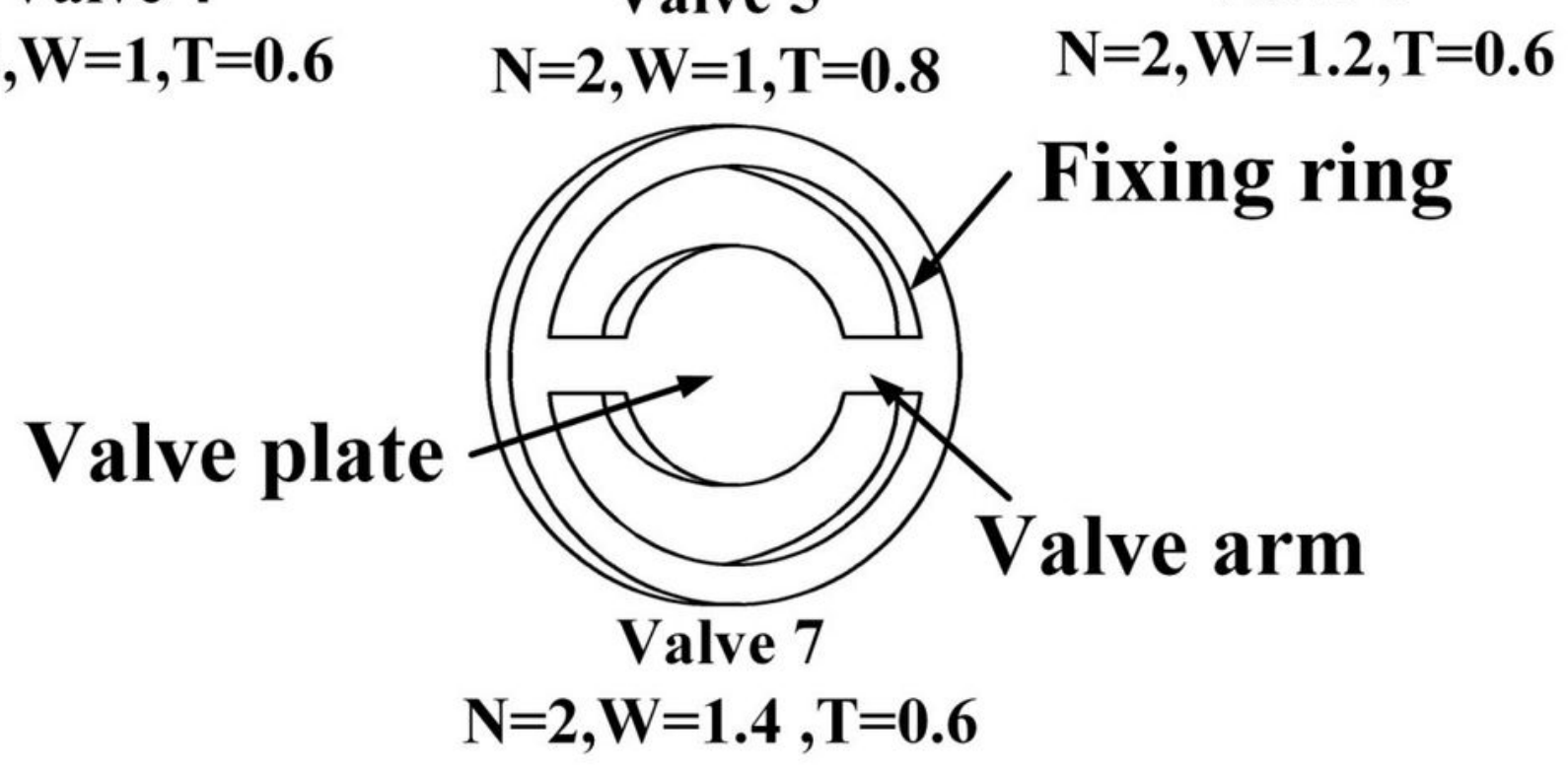

Figure 2

Different valve designs and their geometry parameters (in millimeter): $\mathrm{N}$, valve arm number $\mathrm{W}$, valve arm width $T$, valve thickness 


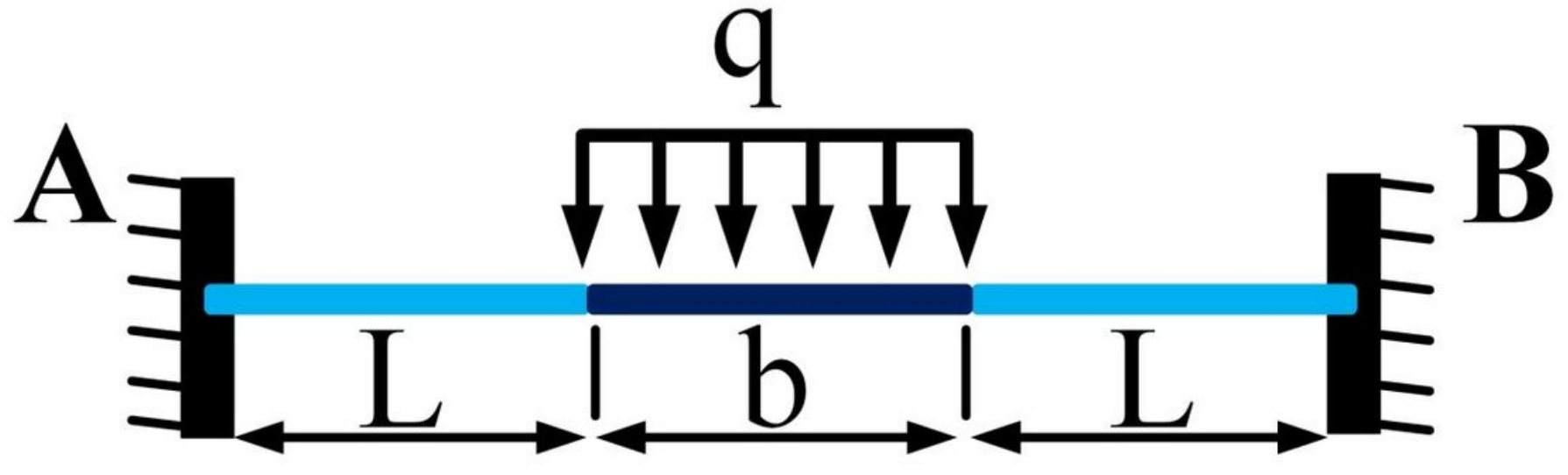

Figure 3

Simulation of valve opening with different valveparameter (a) $N=2, W=1, T=1$ (b) $N=3, W=1, T=1$ (c) $N=4$, $W=1, T=1$ (d) $N=2, W=1, T=0.6$ (e) $N=2, W=1, T=0.8(f) N=2, W=1.2, T=0.6$ (g) $N=2, W=1.4, T=0.6$

(a)

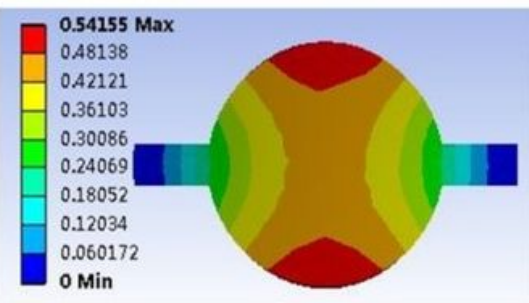

(d)

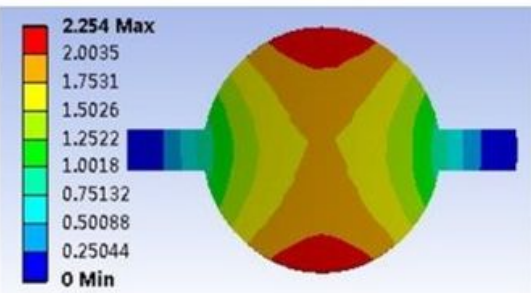

(g)

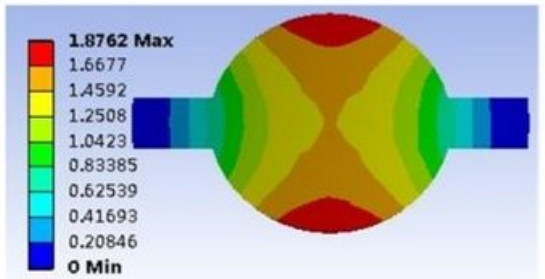

(b)
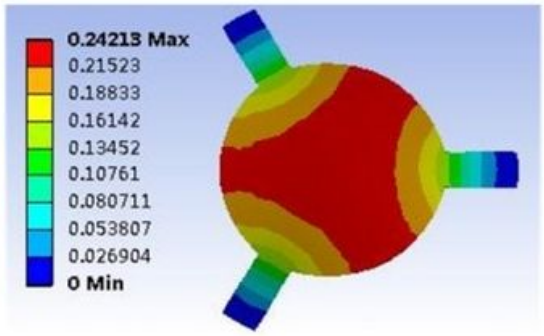

(e)

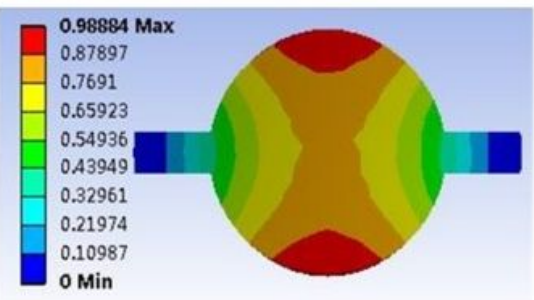

(c)

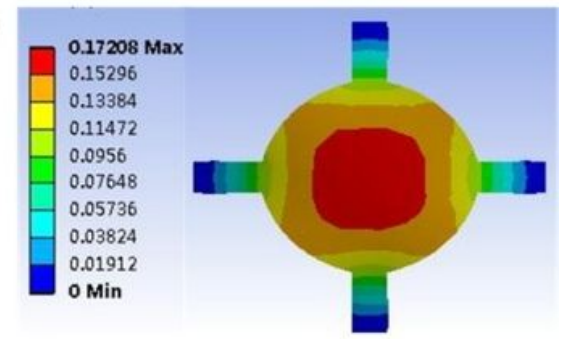

(f)

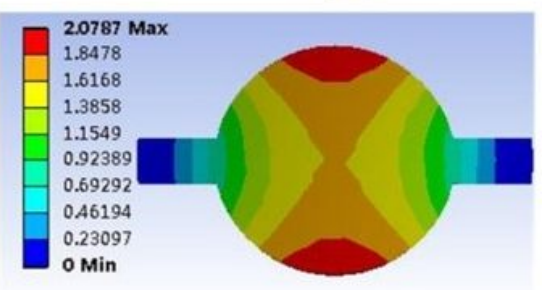

Figure 4

Simulation of valve opening with different valveparameter (a) $N=2, W=1, T=1$ (b) $N=3, W=1, T=1$ (c) $N=4$, $\mathrm{W}=1, T=1$ (d) $N=2, W=1, T=0.6$ (e) $N=2, W=1, T=0.8(f) N=2, W=1.2, T=0.6$ (g) $N=2, W=1.4, T=0.6$ 


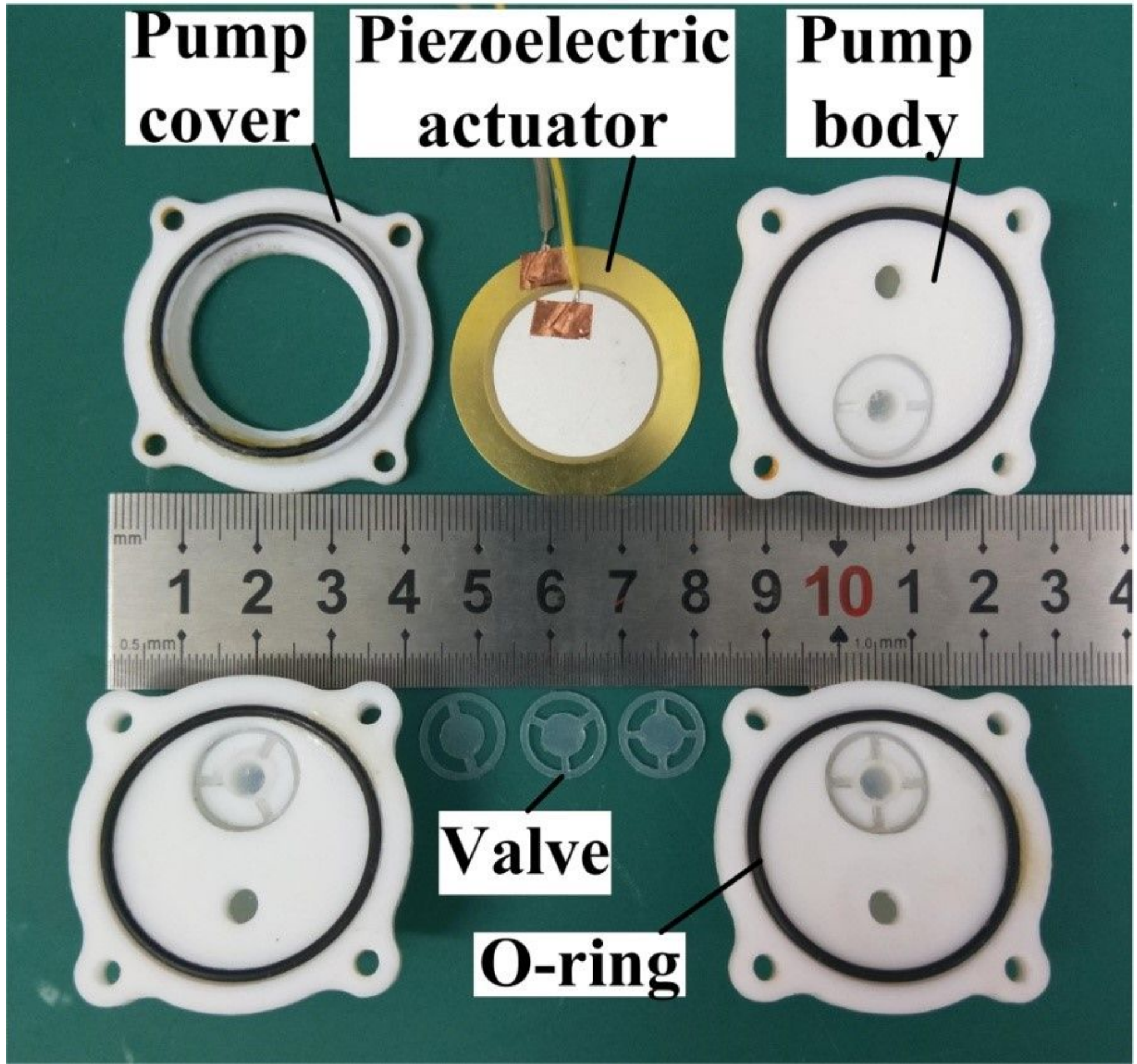

Figure 5

Photo of the prototype pump and valve 


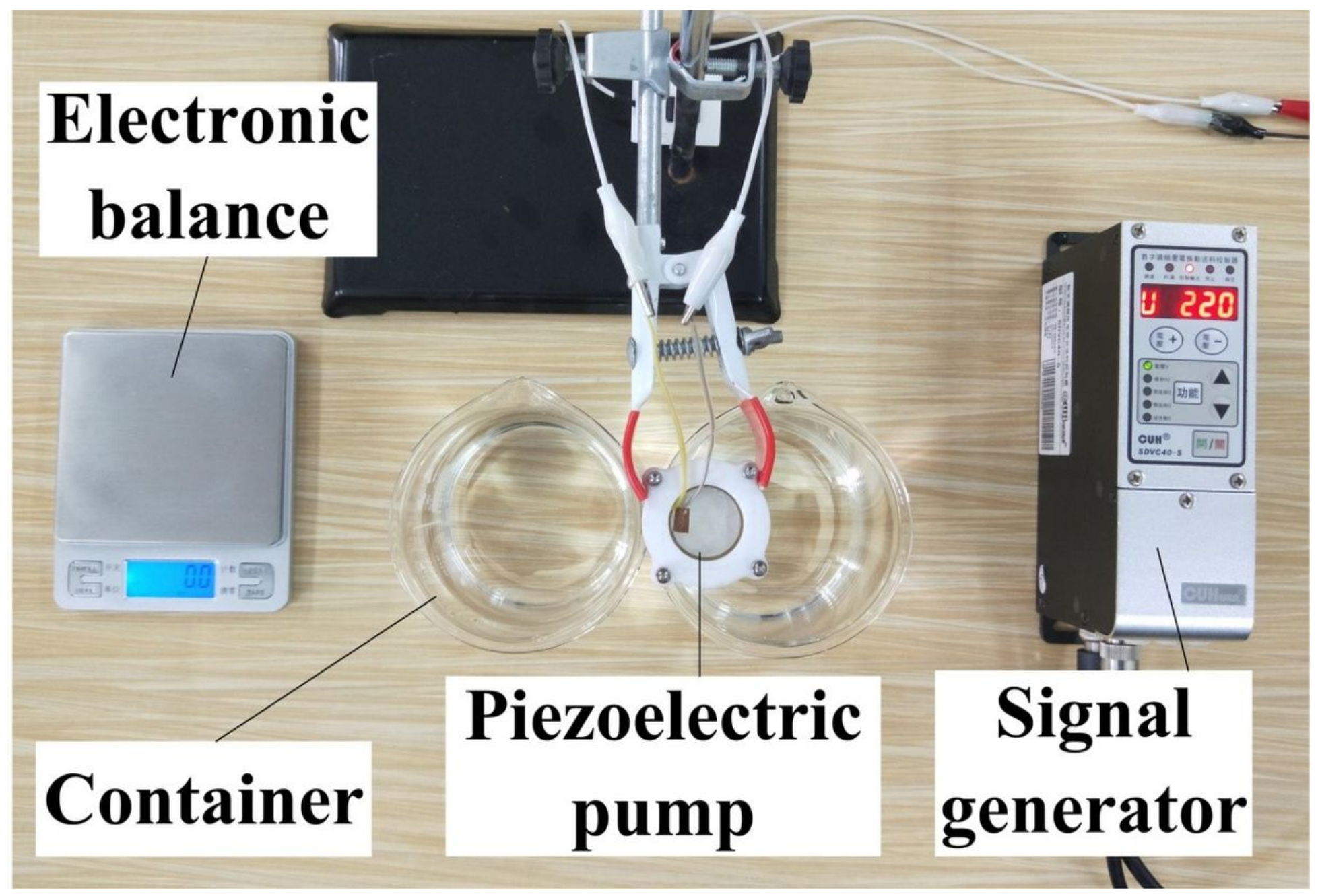

Figure 6

Experimental setups 


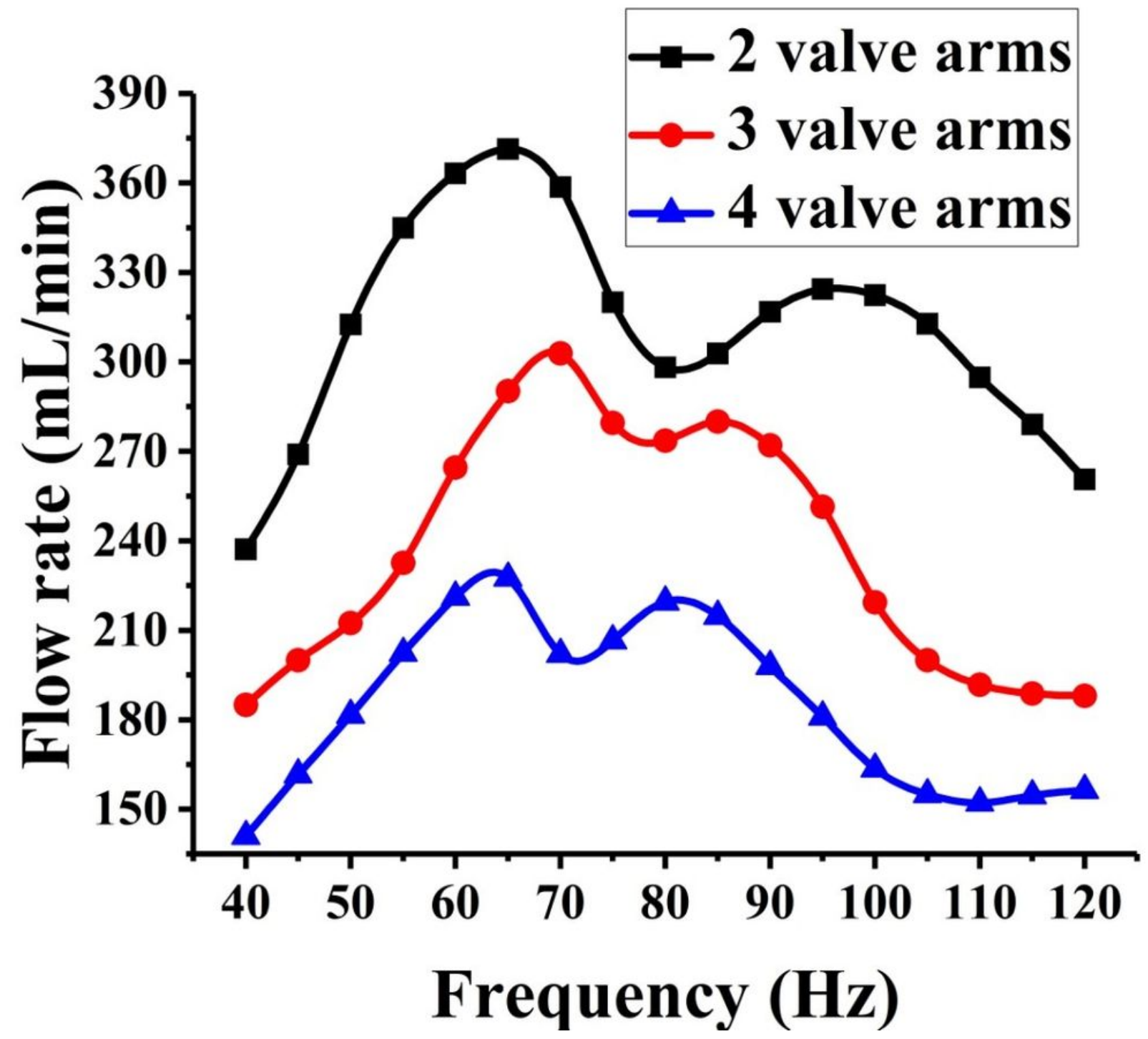

Figure 7

The flow rate curve with frequency under different valve arm number 


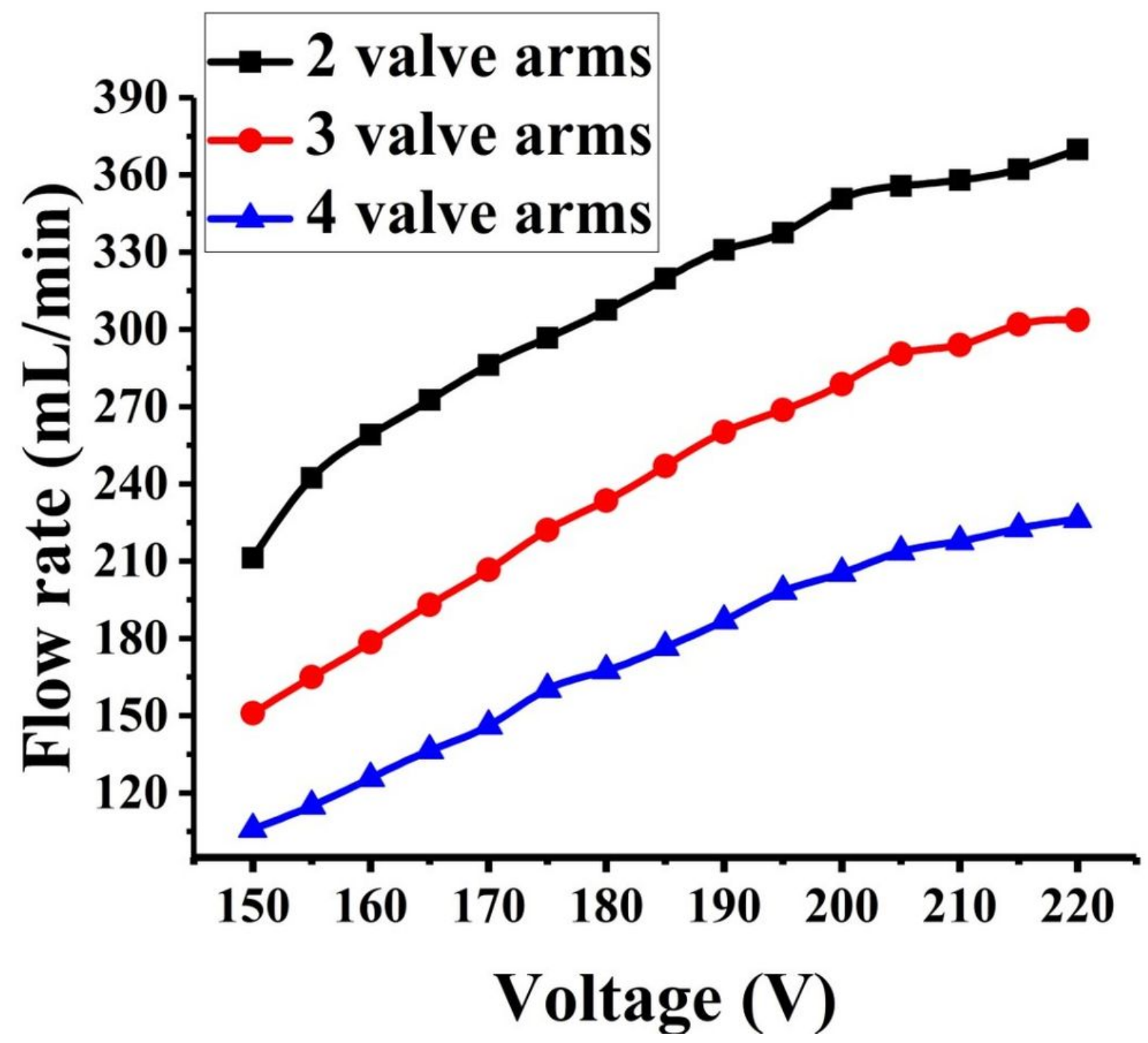

Figure 8

The flow rate curve with voltage under different valve arm number 


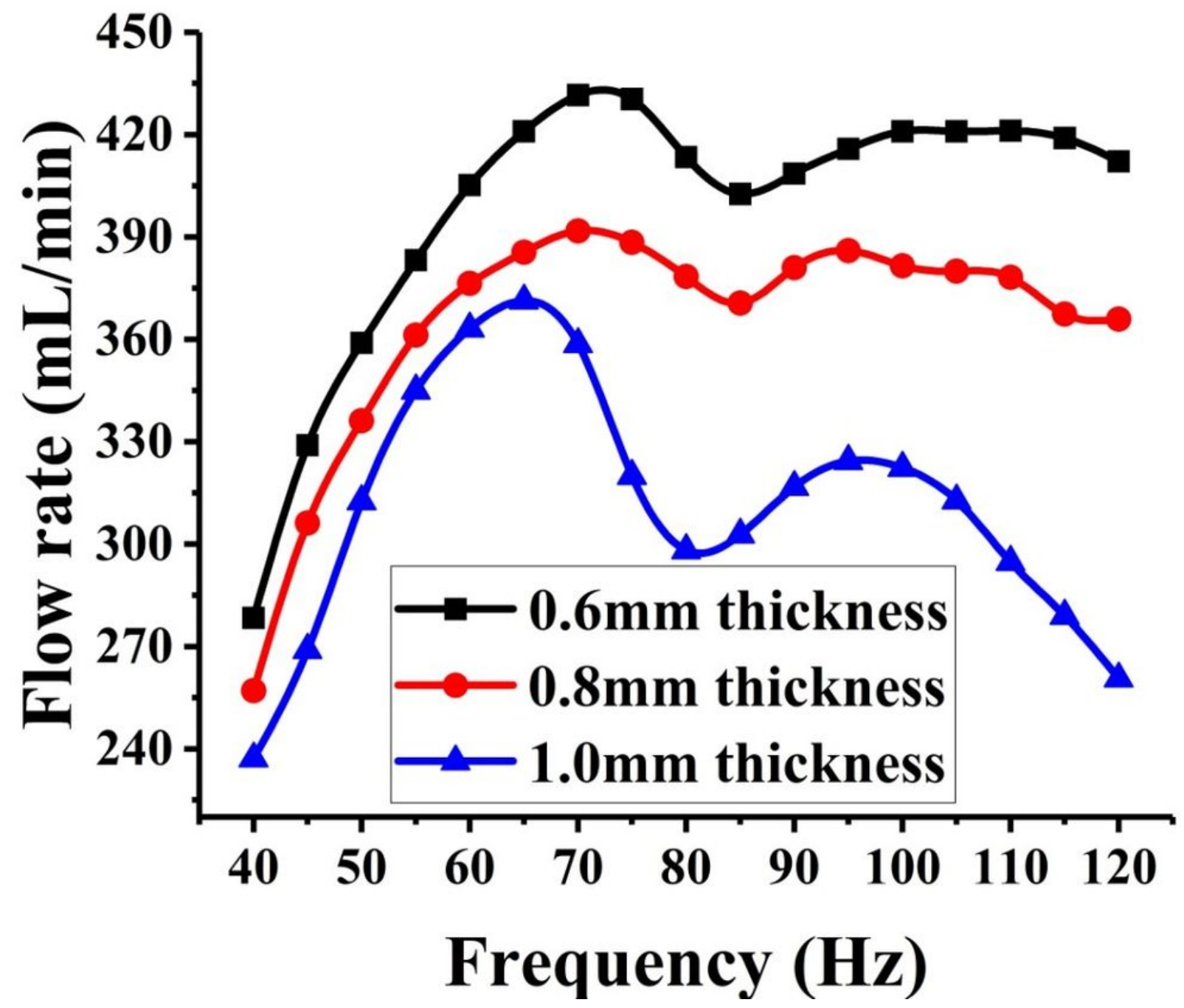

Figure 9

The flow rate curve with frequency under different valve thickness 


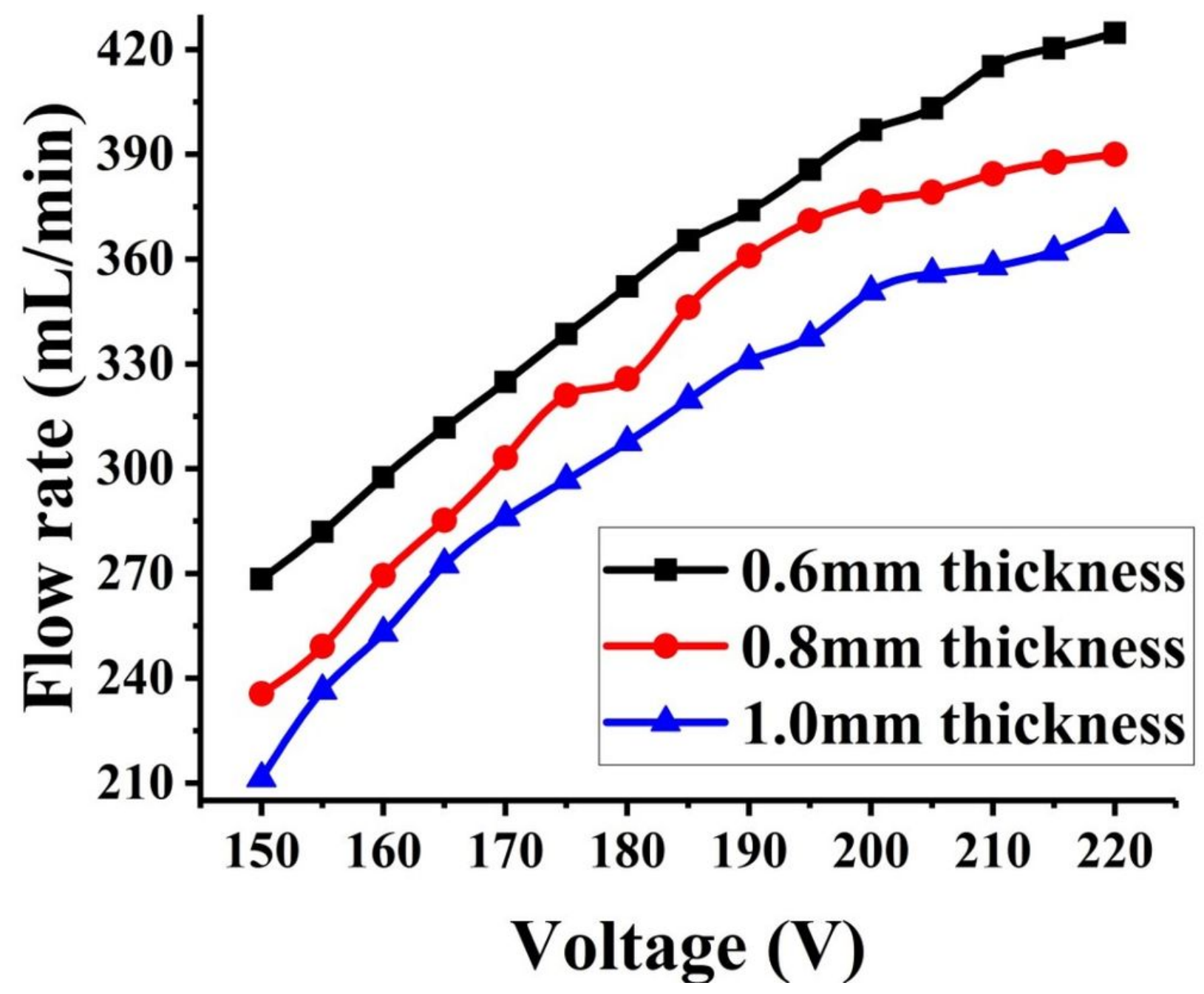

Figure 10

The flow rate curve with voltage under different valve thickness 


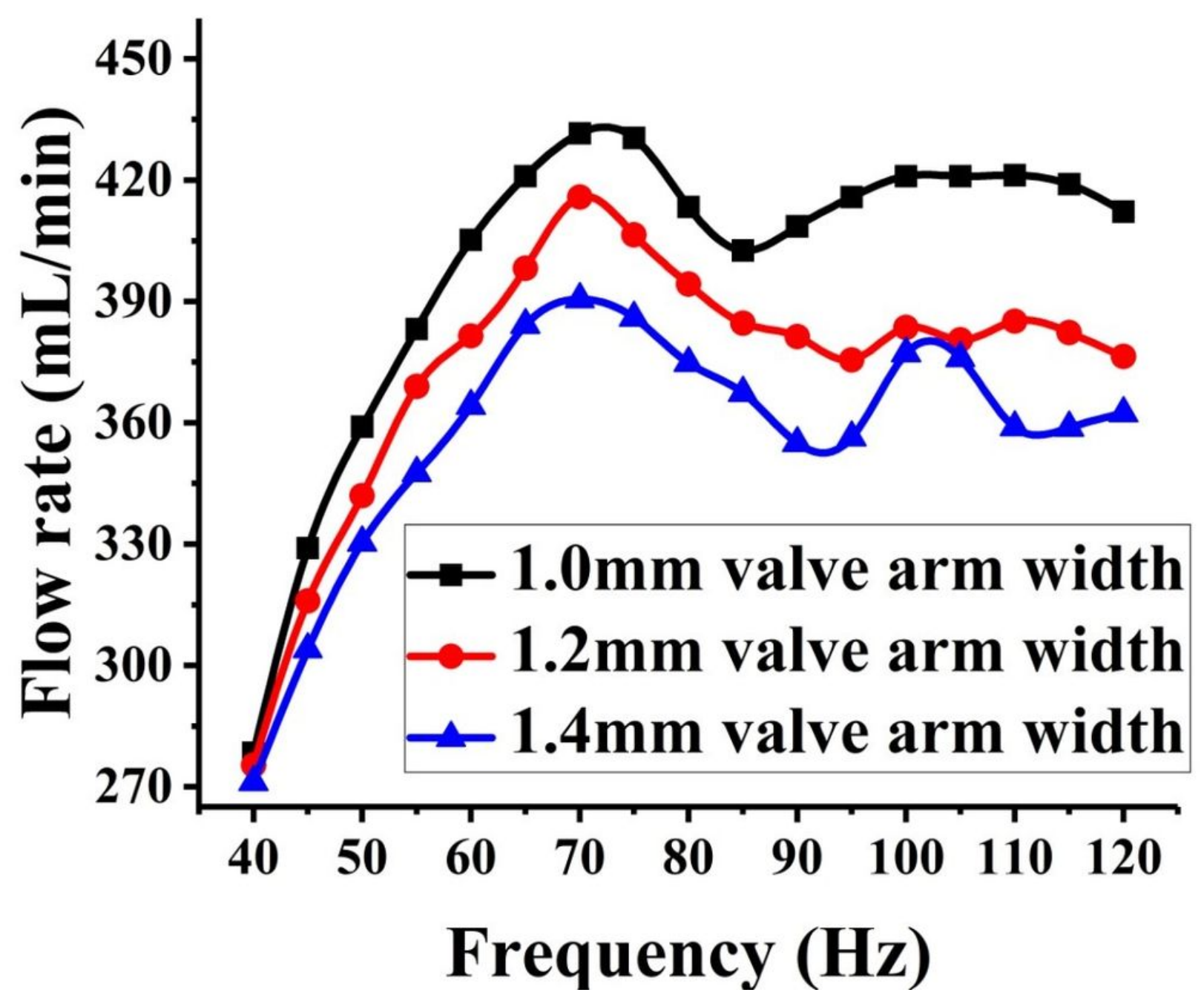

Figure 11

The flow rate curve with frequency under different valve arm width 


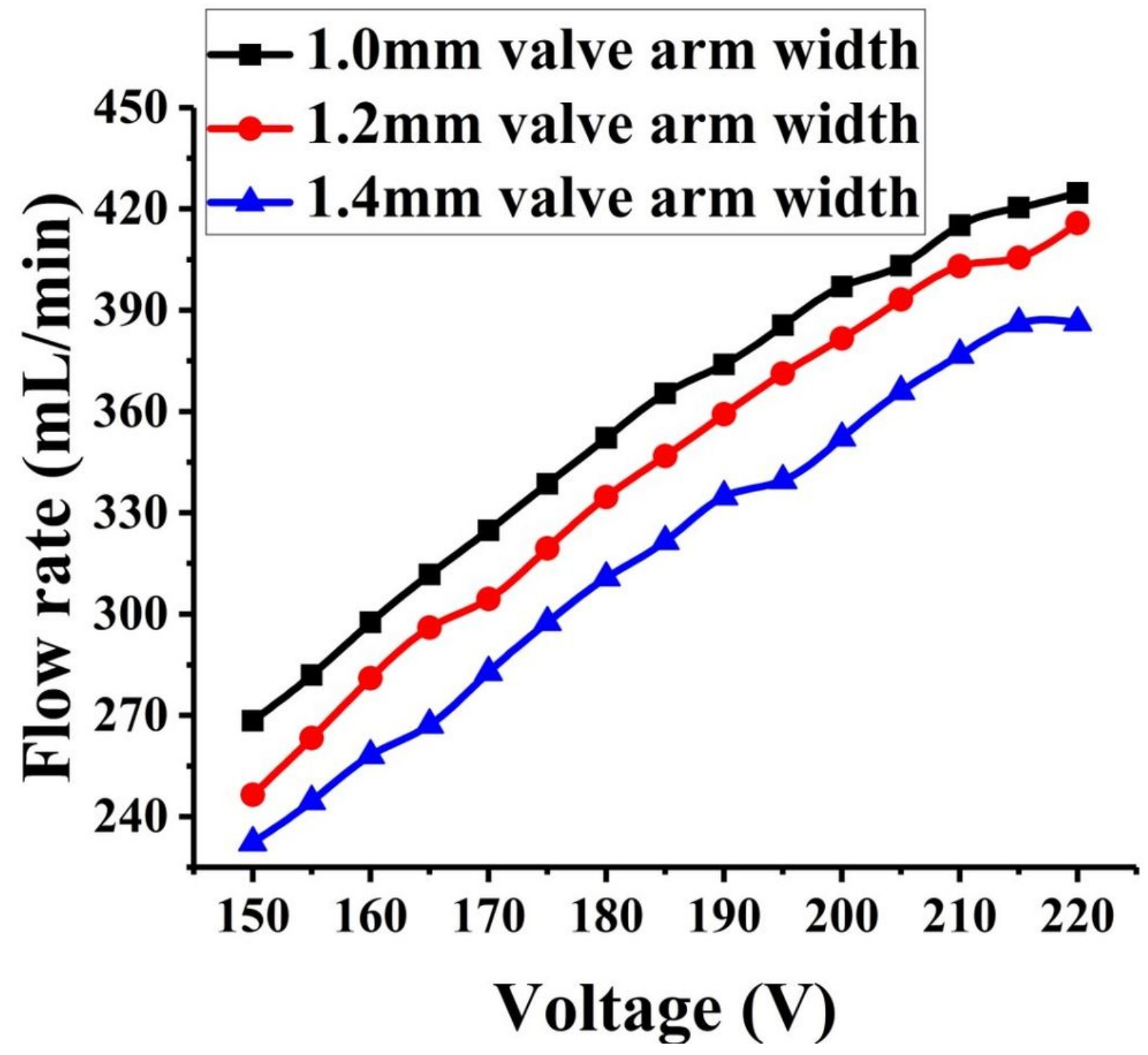

Figure 12

The flow rate curve with voltage under different valve arm width 


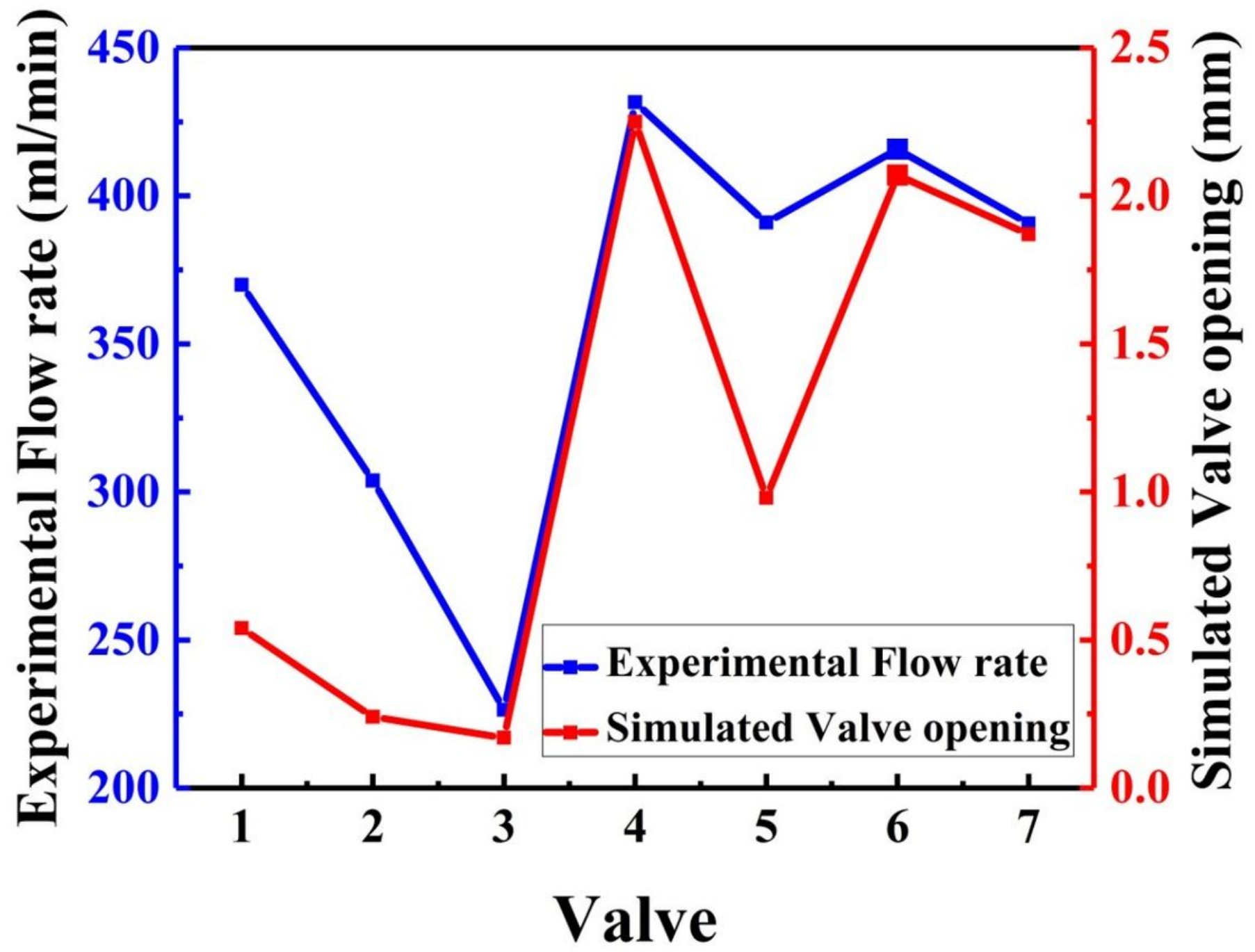

Figure 13

Relationship between valve opening (simulation) and flow rate (experiment) 